\title{
Dying in acute hospitals: voices of bereaved relatives
}

\author{
Diarmuid Ó Coimín ${ }^{1 *}$ (D) Geraldine Prizeman ${ }^{2}$, Bettina Korn ${ }^{3}$, Sarah Donnelly ${ }^{4}$ and Geralyn Hynes ${ }^{5}$
}

\begin{abstract}
Background: Internationally there is an increasing concern about the quality of end-of-life care (EoLC) provided in acute hospitals. More people are cared for at end of life and die in acute hospitals than in any other healthcare setting. This paper reports the views of bereaved relatives on the experience of care they and the person that died received during their last admission in two university adult acute tertiary hospitals.

Methods: Relatives of patients who died were invited to participate in a post-bereavement postal survey. An adapted version of VOICES (Views of Informal Carers - Evaluation of Services) questionnaire was used. VOICES MaJam has 36 closed questions and four open-ended questions. Data were gathered in three waves and analysed using SPSS and NVivo. 356 respondents completed the survey (46\% response rate).

Results: The majority of respondents (87\%: $n=303$ ) rated the quality of care as outstanding, excellent or good during the last admission to hospital. The quality of care by nurses, doctors and other staff was highly rated. Overall, care needs were well met; however, findings identified areas of care which could be improved, including communication and the provision of emotional and spiritual support. In addition, relatives strongly endorsed the provision of EOLC in single occupancy rooms, the availability of family rooms on acute hospital wards and the provision of bereavement support.

Conclusions: This research provides a powerful snapshot in time into what works well and what could be improved in EoLC in acute hospitals. Findings are reported under several themes, including the overall quality of care, meeting care needs, communication, the hospital environment and support for relatives. Results indicate that improvements can be made that build on existing good practice that will enhance the experience of care for dying persons and their relatives. The study adds insights in relation to relative's priorities for EoLC in acute hospitals and can advance care providers', policy makers' and educationalists' priorities for service improvement.
\end{abstract}

Keywords: End-of-life care, Palliative care, Acute hospital, Quality of care, Bereaved relatives, Quantitative, VOICES, Bereavement, Dying, Mortality feedback survey

\section{Background}

In western countries, the location of death has changed significantly in the last century from people dying at home, to dying in institutional settings, such as hospitals or nursing homes $[1,2]$. Acute hospitals have traditionally focussed on the diagnosis, treatment and management of serious and chronic illness; however, they are increasingly the place where care is provided at end of life and the location of death [3]. In the United Kingdom, over half of deaths occur in the acute hospital setting $[4,5]$. Ireland has experienced a

\footnotetext{
*Correspondence: docoimin@mater.ie

${ }^{1}$ End-of-Life Care, Mater Misericordiae University Hospital, Quality and Patient

Safety Directorate, Eccles Street, Dublin 7, Ireland

Full list of author information is available at the end of the article
}

similar trend with $43 \%$ of all deaths occurring in acute hospitals [6].

Internationally, there is an increasing concern about the quality of palliative and end-of-life care (EoLC) provided in acute hospitals. Several reports have highlighted significant deficits and poor care provided to dying patients and their families in this setting [2, 5, 7-11]. However, studies in Ireland, including the National Audit of End-of-Life Care in Hospitals in Ireland [12] and the Survey of Bereaved Relatives, VOICES MaJam, [13] highlight many areas of good practice whilst indicating improvements that could be made to enhance EoLC in acute hospitals.

C The Author(s). 2019 Open Access This article is distributed under the terms of the Creative Commons Attribution 4.0 International License (http://creativecommons.org/licenses/by/4.0/), which permits unrestricted use, distribution, and 
Measuring the quality of EoLC provided in healthcare settings is fundamental to quality assurance and provides information to further enhance and improve patient and family care [14-16]. Information gained from the perspective and experiences of bereaved relatives can provide a better understanding of what is important in EoLC [17] and lead to improvements in the quality of healthcare provided [15]. Understanding the knowledge gaps in this area can lead to changing the message from 'This is what we do' to 'This is how we do it well' ([18] p. 10). EoLC is defined and interpreted in literature and policy internationally in various ways, from care in the last days and hours of life [19], to a broader interpretation of the care provided to people who are likely to die within 12 months, such as people with incurable and life-limiting conditions and those who die unexpectedly, including care provided to relatives [20-23]. The broader definition of EoLC care is utilised for the purposes of this paper.

Gathering data about the quality of palliative and EoLC from patients can pose issues of bias [24, 25] and raise ethical concerns [26, 27]. To overcome such issues, surveys of bereaved relatives are widely undertaken $[24,25$, 28-33]. Studies have found that bereaved relatives are an adequate proxy for patient experiences of care and useful in providing critical insights and perceptions of care experience in the time leading up to the person dying, at time of death and post death bereavement care and support $[25,34]$. Furthermore, relatives indicate that taking part in post-bereavement research places a low burden on them [35] and can be therapeutic [36].

The research was undertaken in two university adult acute tertiary hospitals in Ireland. In addition to the provision of acute services for their catchment area, both hospitals provide services on a national level, typical of other Model 4 tertiary hospitals in Ireland. In 2017, the two hospitals combined, provided treatment to 46,500 inpatient visits in over 1600 inpatient beds and had 112, 000 day patient visits. 539,000 outpatient visits and 108, 900 emergency department visits. Both hospitals have specialist palliative care teams; comprised of a palliative medicine consultant, registrar, clinical nurse specialists and social worker who work office hours. The specialist palliative care team accept referrals from all hospital specialities based on the patients having an advanced, progressive, life-limiting condition with current or anticipated complexities that cannot adequately be managed by the primary physician and team. Similar to the other 38 acute hospitals in Ireland, both hospitals are members of the Hospice Friendly Hospitals Programme, a national initiative of the Irish Hospice Foundation in partnership with the Health Services Executive (state health agency). This programme has been described as a complex sophisticated, multi-faceted advocacy programme creating positive change in the approach to dying, death and bereavement in Irish hospitals [37-39]. The programme published the Quality Standards for End-of-Life Care in Hospitals [40]. These standards, along with the appointment of end-of-life care coordinators in a number of hospitals, have been described as key drivers for quality improvement in EoLC in acute hospitals in Ireland [37-39, 41]. Both hospitals have end-of-life care committees with membership from management, administrative and clinical staff including representation from the specialist palliative care team and public interest representatives. The committee is focussed on the implementation of the Quality Standards for End-ofLife Care in Hospitals [40] and initiatives raised by staff to introduce a palliative care approach for those who would benefit from it in each hospital.

The VOICES MaJam study [13] was undertaken against a backdrop of considerable numbers of people dying in acute hospitals in Ireland [6], the limited research conducted to date on this topic, and the lack of appropriate instruments for evaluating end-of-life care from relatives' perspective. The aim of this study was to ascertain the quality of end-of-life care in the acute hospital setting from the perspective of bereaved relatives. The study also set out to identify aspects of satisfactory EoLC and highlight areas where improvements could be made. It is within these contexts of EoLC that this study took place.

\section{Methods}

\section{Background and design}

This was a quantitative descriptive post-bereavement study which gathered data retrospectively, using a postal survey, from relatives or friends of patients who died in two adult acute hospitals. An adapted version of the VOICES (Views of Informal Carers - Evaluation of Services) questionnaire $[42,43]$ was utilised.

\section{Development of the VOICES MaJam questionnaire}

The National Survey of Bereaved People VOICES is an established method of collecting information on the quality of care provided by the health service to a relative or friend in England [30]. Several studies have utilised an adapted version of the VOICES questionnaire indicating good reliability and validity [2, 44-47].

The VOICES survey uses a validated questionnaire and focusses on those aspects of care which are known to be indicative of the quality of care for patients nearing end of life and their families. The VOICES survey includes, hospitals (including NHS and non-NHS hospitals), hospices, care homes and the persons' home [43]. Our aim was to ascertain the quality of care in two acute hospitals, therefore only questions related to this setting were utilised from the VOICES questionnaire. Permission from NHS England was granted, and the adapted questionnaire was named VOICES MaJam to reflect the adaptation and involvement of both hospitals. This allowed data to be 
collected that would ensure that the respective hospitals were meeting the principles of care outlined in key national standards, specifically the National Healthcare Charter [48], the National Standards for Safer Better Healthcare [49] and the Quality Standards for End-of-Life Care in Hospitals [40].

The VOICES MaJam questionnaire contains 29 core questions and an additional seven questions requesting personal demographic information. In addition, the four open-ended questions from the VOICES original questionnaire were included to gather descriptive data about the care experience during the patient's last admission to hospital. These questions were:

- What, if anything, do you feel was good about the care?

- What, if anything, do you feel was bad about the care?

- Please use the space below if there is anything more you would like to add about the care provided by the hospital to your relative/friend during their last admission.

- Is there is any other help or support that you would have liked to receive from the hospital since your relative's death, please feel free to comment below

The questionnaire was designed to gather data on the quality of EoLC which included the following areas; dignity and respect, pain and symptom management, support provided to families, the care environment, communication and decision-making. Several new questions were developed in areas such as the provision of care in single rooms at end of life, the hospital environment and bereavement support in line with national standards [40, 48, 49], previous research [12], and statutory reports [11], that identified these areas as priorities within the Irish context. Prior to undertaking the fieldwork, the questionnaire was tested for face and content validity with a panel of twelve people who had experienced bereavement.

\section{Sample selection}

Persons recorded as the contact person in the deceased person's healthcare record were recruited for the sample. Relatives of people who died from August 1st 2014 to January 31st 2015 were included. The sample included relatives who were bereaved no earlier than 3 months and no later than 9 months, in line with guidelines highlighted in other research $[50,51]$. All deaths, including sudden and unexpected deaths were included. Demographic data collected in the questionnaire did not include the clinical area where the death occurred. Data relating to the international classification of disease (ICD) code at time of death for patients was also not captured. VOICES utilises the death certificate to recruit their sample as the Office for National Statistics conducts the survey. This was not possible with our study. The exclusion criteria for this study included the following; patients aged less than 18 years of age; patients who did not die in the hospitals; and, relatives with a missing or incomplete address. The combined number of relatives (sampling frame) was 792 (Hospital A: $n=385$ : Hospital B: $n=407$ ) (Fig. 1).

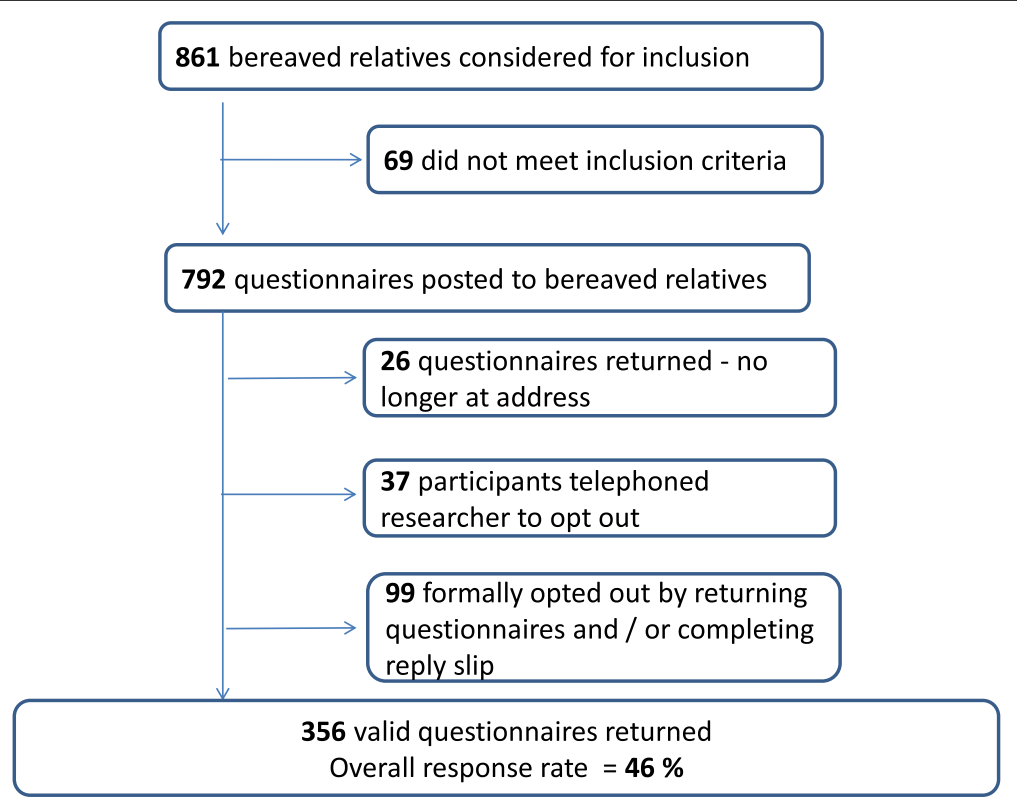

Fig. 1 Sampling process employed 


\section{Data collection}

Data were collected in three waves between May and September 2015 (Fig. 2). Experience from previous VOICES surveys suggests that two reminders are optimal and are associated with a considerable increase in response thereafter $[42,43]$. Respondents were provided with a study information sheet along with an opt-out reply slip, offering them the opportunity to withdraw from the study. Return of the questionnaire was viewed as consent to participate. Information on bereavement supports was included with the survey pack. Relatives were also provided with contact details of the principal investigator in each hospital if they needed to raise any queries or concerns about the study. Wave 2 mailing included the complete survey pack while Wave 3 consisted of a reminder letter only.

A total of 356 valid questionnaires were returned (Hospital A; $n=167$ : Hospital B; $n=189$ ) giving an overall response rate of $46 \%$ (Fig. 2). This is relatively high for a postal survey of bereaved relatives' [32, 45, 52, 53] but comparable with the VOICES survey in England [30] and the National Audit of End-Life-Care in Hospitals [12].

\section{Data analysis}

Quantitative data were inputted into MS Excel and converted to the statistical package IBM SPSS statistics v. 22 [54] for analysis. Frequency and distribution tables were generated for all data. Chi-square tests of significance were carried out to examine the association between several variables. The literature suggests that the key domains of end-of-life care include management of pain relief, other symptom relief, spiritual support, emotional support, personal and nursing needs. Associations with quality of care and these domains were examined. In addition, associations between quality of care and length of stay in hospital and dying in a single occupancy room were examined to see if these had a significant impact on quality of care. A significance level of $p \leq 0.05$ was used for all analyses.

Qualitative data were transcribed verbatim and were coded and analysed using NVivo 10 [55]. Due to the large amount of qualitative data derived from the replies of 286 relatives, a coding frame was developed based on the principles and standards of care outlined in the $\mathrm{Na}$ tional Healthcare Charter [48]; the National Standards

Wave 1: 792 survey packs prepared and sent in May 2015. Packs included:

* information sheet

* questionnaire

* opt-out slip

* bereavement information

* prepaid-envelope

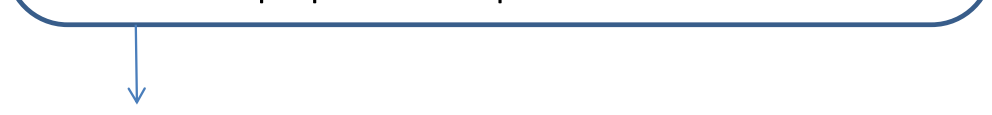

Wave 2: $\mathbf{5 3 4}$ survey packs (contents as Wave 1) prepared and sent three weeks after Wave 1.

Only bereaved relatives who had not already returned a questionnaire or opted out of the study were included in this wave.

Wave 3: 212 Reminder letter only sent three weeks after

Wave 2.

Only bereaved relatives who had not already returned a questionnaire or opted out of the study were included in this wave.

Data collection closed $1^{\text {st }}$ September 2015

Fig. 2 Data collection process employed 
for Safer Better Healthcare [49] and the Quality Standards for End-of-Life Care in Hospitals [40]. Data were analysed thematically using a template analysis framework approach [56]. Five key themes emerged: communication, meeting care needs, hospital environment, dignity and respect and support for relatives. Inter-rater reliability tests were conducted by two independent researchers, indicating a kappa score of 0.62. An EoLC Coordinator from each hospital and experienced researchers from their respective academic partners provided a unique balance of practice and academic expertise in all analyses.

This paper reports on the quantitative findings with some selected qualitative comments that are representative of many similar comments made by bereaved relatives and are included here to provide context. A more comprehensive report of the qualitative findings is published elsewhere [57].

\section{Results}

Demographic details of survey respondents and deceased patients

Three quarters of respondents were female (74.2\%: $n=$ $259)$ and over four in ten $(42.9 \%: n=150)$ were over the age of 60 years. Children of the deceased comprised the largest group (41.1\%: $n=144)$, followed by husband (22.0\%: $n=77)$ or wife (12.9\%: $n=45)$, including civil partner and partner. One in ten $(10.9 \%: n=38)$ were siblings of the deceased (Table 1).

Six in ten $(57.3 \%: n=199)$ people that died were male and half $(50.1 \%: n=178)$ were over 80 years of age, with a further $35.5 \%(n=126)$ between the age of 60 and 80 , many with multiple co-morbidities. The largest proportion (28.9\%: $n=99)$ spent between 2 days and 2 weeks in hospital on their last admission. All other patients' length of stay was almost evenly spread between up to $48 \mathrm{~h}, 2-4$ weeks, $1-2$ months and longer than 2 months (Table 2).

\section{Overall quality of care}

The majority of respondents $(86.8 \%: n=303)$ rated the quality of care as 'outstanding', 'excellent' or 'good'. One in eight $(11.8 \%: n=41)$ respondents rated care as 'fair' or 'poor' (Table 3). The quality of care rated as 'exceptional' or 'excellent' was highest where care was provided by nurses $(79.6 \%: n=317)$ and then by doctors $(71.5 \%$ : $n=299)$ followed by other staff $(68.7 \%: n=226)$ as shown in Table 3. One in 10 respondents rated care provided by hospital doctors ( $8.9 \%: n=30)$ as being 'fair' or 'poor' whilst $5.1 \%(n=18)$ rated care provided by nurses as 'fair' or 'poor'.

Tests for significance indicated that there was an association between overall quality of care and pain relief, other symptom relief, spiritual support, emotional
Table 1 Demographics of respondents

\begin{tabular}{ll}
\hline Gender $(\mathrm{N}=349)$ & $\%(\mathrm{~N})$ \\
Male & $25.8 \%(90)$ \\
Female & $74.2 \%(259)$ \\
Age $(\mathrm{N}=350)$ & $\%(\mathrm{~N})$ \\
18-29years & $0.9 \%(3)$ \\
$30-39$ year & $5.7 \%(20)$ \\
$40-49$ years & $18.9 \%(66)$ \\
$50-59$ years & $31.7 \%(111)$ \\
$60-69$ years & $16.6 \%(58)$ \\
$70-79$ years & $16.8 \%(59)$ \\
80+years & $9.4 \%(33)$ \\
Relationship to the deceased $(N=350)$ & $\%(\mathrm{~N})$ \\
Children & $41.1 \%(144)$ \\
Husband & $22.0 \%(77)$ \\
Wife & $12.9 \%(45)$ \\
Siblings & $10.9 \%(38)$ \\
Other relative or friend & $8.0 \%(28)$ \\
Parent & $5.1 \%(18)$ \\
\hline
\end{tabular}

support and support to stay where he/she wanted, physical comfort needs being met and having adequate privacy (Table 4). There was no significant relationship between quality of care and length of stay in hospital or dying in a single occupancy room.

Table 2 Demographics of the deceased

\begin{tabular}{ll}
\hline Gender $(N=347)$ & $\%(\mathrm{~N})$ \\
Male & $57.3 \%(199)$ \\
Female & $42.7 \%(148)$ \\
Age $(\mathrm{N}=355)$ & $\%(\mathrm{~N})$ \\
18-29 years & $1.7 \%(6)$ \\
$30-39$ years & $3.2 \%(11)$ \\
$40-49$ years & $3.9 \%(14)$ \\
$50-59$ years & $5.6 \%(20)$ \\
$60-69$ years & $10.7 \%(38)$ \\
$70-79$ years & $24.8 \%(88)$ \\
$80+$ years & $50.1 \%(178)$ \\
Length of stay in hospital during last admission $(N=342)$ & $\%(\mathrm{~N})$ \\
$<48 \mathrm{~h}$ & $18.1 \%(62)$ \\
2 days -2 weeks & $28.9 \%(99)$ \\
$2-4$ weeks & $17.3 \%(59)$ \\
$1-2$ months & $16.4 \%(56)$ \\
$>2$ months & $19.3 \%(66)$ \\
\hline
\end{tabular}


Table 3 Ratings of quality of care

\begin{tabular}{llllllll}
\hline Overall quality of care - last admission & Outstanding & Excellent & Good & Fair & Poor & Don't Know & Total \\
& $33.5 \%(117)$ & $36.4 \%(127)$ & $16.9 \%(59)$ & $7.2 \%(25)$ & $4.6 \%(16)$ & $1.4 \%(5)$ & 349 \\
Quality of care - staff group & Exceptional & Excellent & Good & Fair & Poor & Don't Know & Total \\
Doctors & $38.3 \%(129)$ & $33.2 \%(112)$ & $17.2 \%(58)$ & $6.2 \%(21)$ & $2.7 \%(9)$ & $2.4 \%(8)$ & 337 \\
Nurses & $45.0 \%(152)$ & $34.6 \%(117)$ & $14.2 \%(48)$ & $4.4 \%(15)$ & $0.9 \%(3)$ & $0.9 \%(3)$ & 338 \\
Other staff & $35.0 \%(115)$ & $33.7 \%(111)$ & $18.2 \%(60)$ & $5.2 \%(17)$ & $2.1 \%(7)$ & $5.8 \%(19)$ & 329 \\
\hline
\end{tabular}

\section{Meeting care needs}

There was variation in each domain of care as outlined in Table 5.

Bereaved relatives were asked to rate how staff responded to the persons pain during the last admission to hospital. The majority (87\%) rated the management of pain as 'good' or 'excellent' in those who experienced pain during the last admission to hospital. Three quarters $(75.6 \%)$ of those experiencing pain in the last 2 days of life, indicated that pain was 'completely' relieved 'most' or 'all of the time'. Many respondents commented the importance of pain relief on:

"She was made comfortable with pain relief as she was in terrible pain and this obviously gave us some comfort at a terrible time."

However, a number of relatives also commented that pain was poorly managed outside of regular working hours and suggested that specialist palliative care team members should be available out of hours and at weekends to support the management of pain:

"Unfortunately there was no palliative care personnel in the hospital on a sat/sun and I really felt dad was in quite a lot of pain on those days. Emergency \& locum Doctors attended dad but they seemed to lack experience of palliative care $\mathcal{E}$ were not inclined to give pain medication. On the Monday, the palliative care team returned to the hospital and dad's pain relief medication was corrected and he received adequate pain relief. Dad passed away on the Tuesday morning."

A large number of respondents (72.5\%: $n=232)$ indicated that other symptoms were managed at the level of 'good' or 'excellent'. A further 6.6\% $(n=21)$ stated other symptoms were managed poorly. In at least three out of four cases $(73.4 \%: n=250)$ the patient's physical comfort needs were met in the last 2 days of life. Despite this, nearly one in 10 respondents (8.2\%: $n=28)$ indicated that the patient's physical comfort needs were not adequately met (Table 5).

Several respondents commented on the provision of personal care:

"The care of my mother ... was outstanding; my mother was treated with love care and respect until the minute she died ... They were so kind to her, doing small things such as putting curling tongs in her hair.

Table 4 Test of significance results (chi square test for independence)

\begin{tabular}{|c|c|c|c|}
\hline Question & $\mathrm{N}$ & $P$ value $^{a}$ & Phi value ${ }^{b}$ \\
\hline \multicolumn{4}{|c|}{ During last 2 days, overall level of support in following areas: } \\
\hline How well pain was relieved & 247 & $P=.000$ & .28 \\
\hline $\begin{array}{l}\text { Had enough help } \\
\text { to meet personal care }\end{array}$ & 295 & $P=.000$ & .48 \\
\hline $\begin{array}{l}\text { Had enough help } \\
\text { with nursing care }\end{array}$ & 308 & $P=.000$ & .55 \\
\hline Had adequate privacy & 313 & $P=.000$ & .40 \\
\hline \multicolumn{4}{|l|}{ During last admission } \\
\hline Relief of pain & 279 & $P=.000$ & .57 \\
\hline Relief of other symptoms & 280 & $P=.000$ & .68 \\
\hline Provision of spiritual support & 249 & $P=.000$ & .45 \\
\hline Provision of emotional support & 255 & $P=.000$ & .58 \\
\hline $\begin{array}{l}\text { Provision of support to } \\
\text { stay where patient wanted }\end{array}$ & 218 & $P=.000$ & .65 \\
\hline
\end{tabular}

\footnotetext{
a Not applicable or don't know were not included in the analysis
}

${ }^{b}$ Strength of association - with .21 indicating a medium effect and .35 a large effect 
Table 5 Ratings of symptom management and support during last admission

\begin{tabular}{|c|c|c|c|c|c|c|c|}
\hline & Excellent & Good & Fair & Poor & $\mathrm{N} / \mathrm{A}$ & Don't Know & Total \\
\hline Relief of pain- last admission & $48.7 \%(163)$ & $25.1 \%(84)$ & $6.6 \%(22)$ & $4.5 \%(15)$ & $11.3 \%(38)$ & $3.8 \%(13)$ & 335 \\
\hline $\begin{array}{l}\text { Relief of other symptoms - } \\
\text { last admission }\end{array}$ & $42.8 \%(137)$ & $29.7 \%(95)$ & $10.0 \%(32)$ & $6.6 \%(21)$ & $6.3 \%(20)$ & $4.6 \%(15)$ & 320 \\
\hline Spiritual support - last admission & $39.4 \%(129)$ & $21.1 \%(69)$ & $8.6 \%(28)$ & $8.9 \%(29)$ & $10.4 \%(34)$ & $11.6 \%(38)$ & 327 \\
\hline \multirow[t]{2}{*}{ Emotional support - last admission } & $36.1 \%(119)$ & $20.3 \%(67)$ & $12.7 \%(42)$ & $10.0 \%(33)$ & $7.9 \%(26)$ & $13.0 \%(43)$ & 330 \\
\hline & & & $\begin{array}{l}\text { Strongly Agree/ } \\
\text { Agree }\end{array}$ & $\begin{array}{l}\text { Neither Agree nor } \\
\text { Disagree }\end{array}$ & $\begin{array}{l}\text { Disagree/Strongly } \\
\text { Disagree }\end{array}$ & $\begin{array}{l}\text { Don't Know or } \\
\text { N/A }\end{array}$ & Total \\
\hline $\begin{array}{l}\text { There was enough help } \\
\text { to meet physical comfort } \\
\text { needs in last } 2 \text { days }\end{array}$ & & & $73.3 \%(250)$ & $6.7 \%(23)$ & $8.2 \%(28)$ & $11.8 \%(40)$ & 341 \\
\hline
\end{tabular}

This was on top of her usual personal hygiene and nursing care any concerns raised was immediately attended to ..."

Several relatives perceived staff shortages and difficult working conditions as impacting on the provision of patient care:

"We felt the nurses were very overworked and just didn't have the time to give my father the attention he needed and he was reluctant to ask/bother them."

The categories of emotional and spiritual support received respondents' lowest ranking (Table 5). Over half (56.4\%: $n=$ 186) stated that the level of emotional support was 'excellent' or 'good'. One in ten respondents $(10 \%: n=33)$ indicated that emotional needs were poorly met. Several commented on their relatives' experience of emotional support:

"... he was not offered to speak with anyone regarding his diagnosis ... His needs or wishes were not obviously discussed with him as he wasn't offered any spiritual/ counselling support following his diagnosis. This I know would have been important to him. I do not think he suffered physical pain in the last week of his life, but I do know he suffered emotionally which is every bit as bad and it shouldn't be."

"I felt that the care was good because they helped him physically and emotionally."

Six in 10 respondents $(60.5 \%: n=198)$ indicated that the spiritual support provided was 'excellent' or 'good' with one in $11(8.9 \%: n=29)$ indicating it was 'poor'.

\section{Communication}

Awareness about the likelihood of dying and the quality of communication with the dying person were explored. Almost one fifth (18.4\%: $n=64)$ of respondents believed their relative was aware they were likely to die and over one quarter $(27.0 \%: n=94)$ saw it as probable. One fifth
(19.8\%: $n=69)$ indicated their belief that their relative did not anticipate they were going to die, while one quarter (24.7\%: $n=86)$ definitely did not expect it. One in $10(10.1 \%: n=35)$ were unsure about this (Table 6).

Relatives spoke of their experience of hospital staff not recognising or failing to acknowledge and communicate the person was dying. In some instances, this led to the continuation of perceived unnecessary and burdensome interventions:

"No one knows more than family, if close. We have comparisons so we can tell when things are changing. We knew the end was close. Not once could we communicate properly with staff on this ... The day mum died, I was meeting with my sister in the café to work out when to tell my brother to come back from (name of country)... Last time I saw mum, the physio was testing her walking, so I left her early. It would have been better if the physio accepted her saying No and left us to spend a little more time, just chatting and relaxing in the short time before she died." [13]

"On-going tests when my mother wasn't strong enough for them and when it was clear she was dying."

When respondents were asked if the news of their relatives death was conveyed in a sensitive way, over a quarter (26.4\%: $n=58)$ of responding relatives $(n=220)$ answered 'Yes, definitely'. A further one in seven $(13.6 \%$ : $n=30)$ responded 'Yes, to some extent', while $25.5 \%$ ( $n=$ 56) reported that no one told their relative that they were going to die (Table 6). Respondents shared contrasting experiences of how 'bad news' was delivered:"The Doctor's and nursing staff were very sensitive when telling us the difficult news that my mother was going to die."

"Initial diagnosis of [a] fatal condition was delivered in a direct almost brutal fashion by a nurse. This may not have been the intended mode of delivery but this is what happened." [13] 
Table 6 Awareness of and communication about dying

\begin{tabular}{llll}
\hline Did your relative know he/she was likely to die? & & News of likelihood to die told in a caring and sensitive way & \\
\hline Yes, certainly & $18.4 \%(64)$ & Yes, definitely & 26.4\% (58) \\
Yes, probably & $27.0 \%(94)$ & Yes, to some extent & $13.6 \%(30)$ \\
Probably not & $19.8 \%(69)$ & No, not at all & $2.7 \%(6)$ \\
No, definitely not & $24.7 \%(86)$ & Patient did not know was going to die & $18.6 \%(41)$ \\
Unsure & $10.1 \%(35)$ & Not told relative was going to die & 25.5\% (56) \\
& & Don't know & $13.2 \%(29)$ \\
Total & 348 & & 220 \\
\hline
\end{tabular}

\section{Hospital environment}

Seven in 10 respondents (68.9\%: $n=241)$ reported that their relative died in a single occupancy room (Table 7 ). Many respondents, whose relative was cared for and died in a multiple occupancy room, stressed the importance of care in a single occupancy room in the days before the person died:

"We were really hoping that we could have a private room. 2 hours before mam died, we moved into a 2bedded room. It was better than being in the 6-bedded ward but still far from ideal. Not only for us, but for the poor woman who mam had to share with. I was grateful that mam died at midnight and the lady was asleep and the place was quiet and mam had a most beautiful death. ... I think it should be a priority that there is a private room for patients $\mathcal{E}$ family to go to die. EVERYONE DESERVES THAT."

It would have been less distressing for all if he had his own room earlier. We were trying to keep him calm and other people on the ward were not that sick. I could never complain about this, his care as it was, was $100 \%$ excellent."

Respondents commented on both the significance of a single occupancy room at end of life, and the impact on their dying relative and the family when a single room was not available:

"They allowed us stay with our mother, there was no single room available but the staff went over and beyond to get us a single room for the last two days of her life."

"I cannot speak highly enough about the care the nursing staff gave to my relative. Unfortunately, the lack of availability of a single room was an issue. I was with my relative when she died as I stayed all night; she passed away early in the morning. My family (5 siblings) could not all stay and were not with my mum when she died. We were fortunate that she was sharing with a lovely lady who was VERY understanding of the constant visiting."

"... when she was moved to a single, private room, there was unrestricted visiting and overnight stays were allowed. This was very helpful as she died... while we were still present."

"I feel that a private room should have been offered as it was felt that we couldn't talk loudly and share experiences, a lot of final speeches were whispered which I felt took away from the final goodbye."

Over two thirds of respondents (69.1\%: $n=235)$ agreed there was enough privacy, however, almost one in six

Table 7 Hospital environment and support for relatives

\begin{tabular}{llll}
\hline $\begin{array}{l}\text { Care in a single room } \\
\text { at time of death }\end{array}$ & Yes & No & Not sure \\
Adequate privacy in & $68.9 \%(241)$ & $26.3 \%(92)$ & $4.8 \%(17)$ \\
last 2 days of life & Yes & No & N/A or Don't Know \\
Availability of & $69.1 \%(235)$ & $17.4 \%(59)$ & $13.5 \%(46)$ \\
family room & Yes, found helpful & No/Don't Know & Did not receive \\
Support for relatives & $71.1 \%(219)$ & $4.9 \%(15)$ & $24.0 \%(74)$ \\
at time of death & Yes, definitely & Yes, to some extent & No/ Don't Know \\
Sensitive care & $69.0 \%(240)$ & $24.1 \%(84)$ & $6.9 \%(24)$ \\
after death & Yes & Yes & No/ Don't Know \\
\hline
\end{tabular}


(17.4\%: $n=59)$ indicated that there was not enough privacy.

Another aspect of the hospital environment explored was access to or availability of a family room on the ward. One in four respondents $(24.0 \%: n=74)$ did not have access to a family room. Almost all $(98.6 \%: n=219)$ of those who had access to a family room found it helpful. Many commented on the importance of having a family room on acute hospital wards and the impact it had on their experience of care and privacy:

"We as a family never had a family room to talk to mam in private, everyone can hear your business in wards. Even on her last day when we were advised to come in. We had nowhere to make a cup of tea or sit in private we had to use a storage room, which just adds to your distress."

The provision of dedicated family rooms that are warm and welcoming spaces, offering comfortable seating, free tea or coffee making facilities and a sofa bed to allow a family member stay overnight were identified by relatives as important resources. In the absence of family rooms, respondents reported sitting in open plan waiting areas and discussing confidential information including being given 'bad news in public spaces and corridors'.

\section{Support for relatives}

More than two thirds of respondents (69.0\%: $n=240$ ) said that they had definitely been given enough support at the time of the death. A further quarter (24.1\%: $n=$ 84) said that they had to some extent (Table 7).

The majority (94.6\%: $n=331$ ) of respondents indicated they were cared for sensitively after their relative died. A minority (4.0\%: $n=14)$ indicated they were not. One relative for example, commented on the support received at this time:

"Quick access to my mother's body in a private room. Quick arrival of a priest. Staff checking on me regularly yet giving privacy to grieve. Tea, sandwiches for family when they all arrived. No rush to leave the room, all at my pace."

However, others had a different experience and would have liked more information about what to do at the time of death:

"More practical support the day of his death no one seemed to know what happened following the death e.g. arrangements for our undertaker to remove the body from the morgue etc. considering we had such a journey, staff were not helpful."

One in six respondents (16.5\%: $n=57$ ) had spoken with someone from the hospital about their feelings around their relative's illness and death and found this helpful; 28.6\% $(n=99)$ did not but would have liked to and a further $53.5 \%(n=185)$ did not wish to speak with anyone about their feelings. One per cent of respondents reported having spoken with someone and reported finding this unhelpful. Social workers, doctors and nurses were the source of contact for the majority of respondents (Table 8). Relatives commented on the support they received or required at this time:

"We deeply appreciate receiving a letter from the staff expressing their sympathy. Thank you."

"We would have liked to receive a bereavement booklet and information on what services were available to us."

\section{Discussion}

This study is the largest survey of bereaved relatives, in an acute hospital setting to be conducted in Ireland to date and from that perspective, findings bring previously unknown information into the public domain. Our study findings add to the international picture regarding endof-life care in acute hospitals and will enable hospitals to understand important elements of end-of-life care from the perspective of bereaved relatives and to identify priorities for service improvement.

This research found that several aspects of care influenced the provision of EoLC for people in an adult acute hospital setting in Ireland, including quality of care, care needs being met, quality of communication, the hospital environment and support provided for relatives. While other studies using adapted versions of VOICES focussed on specific illnesses [2] and research focus [45, 47], similar themes emerged in this research. Findings from other published research $[17,58]$ on end-of-life care in hospital settings are also reflected here.

\section{Quality of care}

This study was conducted to establish the quality of EoLC provided in two adult acute hospitals. It is encouraging to find that the results indicate that the quality of care at end of life was generally considered to be high by respondents. This reflects well on the quality of care in both hospitals and compares favourably with research conducted on the quality of EoLC internationally $[9,30$, 59, 60]. However, bereaved relatives also indicated elements of care which could be improved. Respondents' narrative comments provided significant insights into the diversity of care experiences and offer important suggestions for improvements that should be considered as part of the provision of EoLC in acute hospitals. 
Table 8 Spoke to someone about death of relative

\begin{tabular}{|c|c|c|c|c|c|}
\hline \multirow[t]{2}{*}{$\begin{array}{l}\text { Spoke to someone about } \\
\text { feelings around death }\end{array}$} & $\begin{array}{l}\text { Yes, found } \\
\text { it helpful }\end{array}$ & $\begin{array}{l}\text { Yes, found } \\
\text { it unhelpful }\end{array}$ & $\begin{array}{l}\text { No, did not, but } \\
\text { would have liked to }\end{array}$ & $\begin{array}{l}\text { Did not wish to } \\
\text { speak with anyone }\end{array}$ & Total \\
\hline & $16.5 \%(57)$ & $1.4 \%(5)$ & $28.6 \%(99)$ & $53.5 \%(185)$ & 346 \\
\hline \multirow[t]{2}{*}{ Professional spoken to } & Doctor & Nurse & $\begin{array}{l}\text { Social Worker / } \\
\text { Bereavement Counsellor }\end{array}$ & Chaplain & Don't Know/Other \\
\hline & $28.2 \%(29)$ & $24.3 \%(25)$ & $29.1 \%(30)$ & $11.7 \%(12)$ & $6.7 \%(7)$ \\
\hline
\end{tabular}

Similar findings have emerged from the use of the VOICES tool [2]. This study highlights that the quality of EoLC during the last admission to hospital is multifaceted involving many factors including, but not limited to, the provision of holistic care, management of symptoms, good communication and the hospital environment.

\section{Meeting care needs}

Quality care at end of life follows a palliative care approach which addresses physical symptoms, social, emotional and spiritual needs [61]. The assessment and management of physical pain and symptoms other than pain is a major focus of EoLC $[32,62]$. The dying person's physical problems must be anticipated and proactively addressed in order to provide comfort and maximise quality of life.

Studies $[12,63]$ have found that the relief of pain and symptoms other than pain were well managed by hospital staff which was reflected in this study. However, our findings contrast with other studies [50,64] where pain was considered to be poorly managed. Where respondents in this study suggested improvements relating to poor symptom management, these centred on the lack of access to specialist palliative care expertise at weekends and out of hours. These findings mirror international findings on EoLC [8] and reports of the underfunding of specialist palliative care services in England $[65,66]$ and Ireland $[67,68]$. The provision of face-toface palliative care services in acute hospitals from at least 9 am to $5 \mathrm{pm}$ Monday to Sunday has been recommended $[69,70]$. The importance of managing pain and other symptoms was indicated by relatives when they spoke of the upset they experienced where they were not managed and the impact it had on the dying person, also noted by Dunne and Sullivan [71].

The provision of emotional and spiritual support and meeting the needs, wishes and preferences the person who is dying in these domains of care is fundamental to good EoLC and is recognised in many countries in policy $[21,60]$, professional standards and competencies [20, 72], and in research studies [73-75]. As in other studies [24, 59, 76], emotional support was one domain of care where relatives indicated needs were not fully met. Enhancing the provision of emotional and psychological support for the dying person and their family was required as part of EoLC in hospitals has also been identified in research [15]. Living with a lifelimiting illness and awareness of the imminence of one's own death may heighten concerns about issues related to quality of life, uncertainty about the future and death. The role of medical staff in the provision of emotional support at end of life has also been highlighted [77]. According to Mistry et al. [16] EoLC should include a holistic perspective of care reporting that "being free of emotional and spiritual burden, including the fear of dying, was considered critical in ensuring the patient's remaining days are mentally 'pain free'” [16: 3].

Several studies have considered the barriers to the provision of emotional support. These included low participation of acute hospital staff in further education on the topic [78], distancing strategies to ensure their own emotional wellbeing [78], busyness [63] and staff shortages [15].

Ensuring spiritual care and support needs are met is a quality marker of good EoLC [21, 40, 79, 80]. Provision of spiritual care that responds to the needs and preferences of the person who is dying and their relatives are core elements of holistic palliative care [61]. However, in this study, relatives indicated there was limited support of the persons' spiritual care needs which has also been found in other studies $[24,33]$. There is evidence that the provision of spiritual care, for those who are seriously ill, is somewhat neglected in acute hospitals $[9,30,81]$ and it has been recommended that physicians should receive adequate training in evaluating spiritual needs [82]. Research studies report that patients valued nursing staff meeting spiritual care needs, finding it a source of comfort and meaning [83] and noted the importance of spirituality in coping with a terminal illness [82, 84-86]. Many healthcare facilities, including acute hospitals have pastoral care teams, or a hospital based chaplain, who specialise in attending to the spiritual needs of patients and their family members. However, the provision of spiritual support is also a core element and competency of all healthcare staff $[86,87]$. While addressing patients' spiritual needs is key to good EoLC, there is limited clinical guidance on how clinicians might best meet these needs [80]. Koenig [86] suggests that nursing staff or social workers should conduct two-minute spiritual "screening" evaluation of all patients and when spiritual needs are identified, the health professional would then 
make a referral to pastoral care services. However, barriers to meeting patient's spiritual care needs have previously been identified as a lack of confidence by healthcare staff [81] and discomfort over discussing such issues [86].

Care of people who are dying requires attention to their personal care, comfort and support needs. Whilst the majority of respondents in this study reported the dying person received adequate care and support, some relatives reported that there was inadequate support at times, specifically with personal care as described elsewhere [8, 28, 45, 88]. Respondents reported that inadequate care was a systems related issue and cited perceived staff shortages as the main reason for unmet personal care needs.

The perceived lack of support with personal care and the unmet needs associated with the provision of emotional and spiritual support are areas for further improvement to enhance the EoLC experience.

\section{Communication}

Fundamental to all aspects of healthcare and particularly to good EoLC, is timely, sensitive and clear communication with the person who is seriously ill and their family members [89]. As reported in other research [24, 45], the results of this study indicate that staff need to be more proactive and sensitive in their communication to ensure clarity and more open discussions about prognosis and the possibility of dying so that wishes and preferences are met. Good communication centres on respecting patients' dignity and privacy whilst ensuring their wishes and needs are heard and understood. This is of critical importance when the discussion with the patient and family is about dying. It is also recognised that there can be considerable uncertainty in identifying when someone is dying and at times changes can happen suddenly and unexpectedly. Open communication on issues related to EoLC is crucial so that the person is fully enabled to participate in making informed decisions about care at end of life. In addition, studies $[90,91]$ have shown that timely advance care planning (ACP) has a positive effect on patients and their families, including a reduced burden by surrogate decision makers. Through skilled and timely engagement in ACP, healthcare professionals can contribute to families' better assessment of the quality of dying and death [92, 93]. Lack of discussion about EoLC may lead to anxiety about dying [92] with plans left incomplete and conversations not had. Other studies $[24,59,94]$ have reported on bereaved relatives' expectation that they should be better prepared by staff for the person's death including indicating timeframes associated with prognosis [95]. Poor communication, particularly around the time leading up to the person's death, is well documented $[24,59,94,96]$ and is an area for further improvement [28]. Competence to communicate with patients can be enhanced by training modules [15] and courses where healthcare staff learn how to conduct difficult conversations [97].

\section{Hospital environment}

Several aspects of the hospital's physical environment has been identified by patients, families and healthcare staff as being important in the provision of good EoLC, including the levels of privacy, care in a single occupancy room, hygiene, atmosphere and noise levels and family facilities [98-104]. Several researchers [100, 105, 106] have indicated that care for the dying person in multiple occupancy rooms was deemed inappropriate due to the noise level and the busy atmosphere. McKeown et al. [98] found that care outcomes were perceived as better when care was provided in a single occupancy room. In addition, international experts $[69,70]$ recommend the availability of single rooms in the provision of palliative care. In our study, the majority of respondents received care in a single occupancy room and the majority were very satisfied with their care. However, where care was provided in multiple occupancy rooms, some respondents described such rooms as being inadequate and intrusive on the experience of the person dying and their family members and advocated the importance of care being provided in a single occupancy room. It was evident in the free text comments, that without access to a single room, relatives were unable to spend treasured time together to say their goodbyes in a relaxed comfortable and private environment which mirrors the results of studies conducted by Dunne and Sullivan [71] and Stajduhar [28].

Families spend long days and many hours with relatives who are seriously unwell or dying in acute hospitals. Similar to other studies [71, 99, 106], some relatives in this study, through free text comments, advocated the importance of having appropriate family facilities on acute hospital wards, providing privacy to meet with their family members and healthcare staff. The importance of enhancing the environment to promote dignity, privacy and therefore improve the care experience for patients and their relatives through the development of family rooms is reported elsewhere [41, 107-111]. While statistical analysis indicated no significant relationship between quality of care and death in a single occupancy room, factors including the provision of EoLC in a single room and access to family friendly facilities were reported by respondents in our study as helpful resources at this time.

\section{Support for relatives}

International research $[112,113]$ in the areas of oncology and palliative care has found that staff provide bereavement support to varying degrees as part of their routine practice. Bereavement support is a core function 
of palliative care, with Small et al. ([114] p. 1) suggesting that there is a need for "continued support for vulnerable carers after the death". However, other research [115] has found that bereavement follow-up tends to be less frequent in acute hospitals. Harrop et al. [116] report relative's difficulties in accessing support, highlighting the absence of available services and lack of information. The barriers to the provision of a post-death bereavement support have been explored in research and are predominantly related to staffing and funding [115]. Many relatives reported in this study their preference that hospital staff make contact with them, following the death of their family member which has been reported in other research [33, 117]. Furthermore, other forms of support, such as a bereavement letter with bereavement support information, and the provision of bereavement support evenings by hospital staff were viewed favourably by respondents. Studies [118, 119] have shown that organised bereavement support evenings can be a form of comfort and have a positive impact on relatives' grieving process, reducing levels of anxiety and depression. Bereavement services held in hospitals can act as 'endings' and are seen as an important component of care in the acute hospital setting [120].

\section{Strengths and limitations of this research}

To date, this is the largest survey of bereaved relatives conducted in two acute hospitals in Ireland. Findings from this study contribute to our understanding and increase our knowledge of what is important to people at end of life. Bereaved relatives describe what good EoLC should look like and highlight areas where care can be improved in acute hospitals. The findings reflect those in similar studies, therefore, adding to and strengthening international research in this specific area. Utilising an adapted version of the VOICES questionnaire, including open-ended questions, allowed for insights to be gained into how care could be improved at end of life.

We acknowledge that the study is limited somewhat by representing the views of bereaved relatives who choose to respond. We do not have demographic information on relatives who did not respond for comparison. In addition, the study does not explore the views of patients directly. While the reliability of proxy reporting has been questioned by some [121-123], others express confidence about its reasonable validity and correspondence with patient's views [124-126]. Study respondents were in the main from a specific region in Ireland, and therefore may not be representative of bereaved relatives countrywide. Research challenges relate to the fact that the research was carried out from an 'insider' position thus raising issues of potential bias however; it could also be argued that this provided a heightened sensitivity to the data collection and analysis process. Despite the above limitations, the data has strong validity and represent the direct experience of care in two adult acute hospitals.

\section{Implications for practice and research}

This study took place within the context of both hospitals' Hospice Friendly Hospitals Programmes. Study findings and recommendations now form a key part of the hospital's systems strategic quality improvement plans for EoLC. A quality improvement plan was devised to address the study findings and recommendations, which are being implemented by each hospital's end-oflife care committee. A member of the hospital executive management team chairs this committee. System wide initiatives from this plan are discussed at the Quality and Patient Safety Steering Committee whose focus is on quality improvement throughout each hospital. Since completion of the study, implementation of key recommendations has resulted in measurable improvements such as an increase in the number of patients dying in single occupancy rooms and the completion of several projects to enhance the environment for dying patients and their relatives. Other initiatives have included working with colleagues, in the Hospice Friendly Hospitals programme, on the development of a booklet on the provision of information about what to expect when someone is dying [127] and heightened awareness and improvements in communication to bereaved families when there is a Coroners Post Mortem. In addition, EoLC training and education for staff has been revised to improve communication and enhance the provision of spiritual and emotional support informed by bereaved relatives' recommendations. By collating data and advocating for previously unheard patient's and relative's narratives, this research has filled a gap in how acute hospitals can measure EoLC in a meaningful way that leads directly to quality improvements. Further research is required to explore if the issues raised here are reflected in other acute hospitals.

In an Irish context, seeking the views of bereaved relatives should be considered by all hospitals and healthcare settings to ascertain the quality of care at end of life and to support the development of quality EoLC. A recommendation from this study is that this should be conducted at a national level to support benchmarking and EoLC quality improvements, which is already in existence in other jurisdictions [30].

\section{Conclusion}

This paper adds to the body of research ascertaining the quality of EoLC in acute hospitals from the perspective of bereaved relatives. Overall, respondents rated the quality of care as high; however, areas of care which could be improved were also identified. Our findings can advance acute hospital care providers', policy makers' 
and educationalists' understanding of bereaved relatives experiences and priorities for service improvement.

This research has provided a powerful snapshot in time into what works well and what should be improved to enhance care at end of life. Furthermore, it indicates that a systems-wide approach needs to be undertaken to enhance the experience of care for all dying persons and their relatives.

\section{Abbreviations}

ACP: Advance Care Planning; EoLC: End-of-Life Care

\section{Acknowledgements}

We sincerely thank all the bereaved relatives who took part in the survey. We really appreciate the time, dedication and effort they made to complete the questionnaire. We would like to thank Margaret Codd and Mairéad Curran for their contributions to the design of the study, fieldwork and report preparation stages of this study.

This study was a collaboration between the Mater Misericordiae University Hospital, St. James's Hospital, the Trinity Centre for Practice and Healthcare Innovation at the School of Nursing \& Midwifery, Trinity College Dublin and the School of Social Policy, Social Work and Social Justice, University College Dublin.

We are grateful to the NHS England for permission to adapt the questionnaire used for the National Survey of Bereaved Relatives VOICES (Views of Informal Carers - Evaluation of Services).

Some of the text in the main body of this paper has been reproduced from the authors' published research report [13]

\section{Authors' contributions}

DÓC and BK conceived the study, participated in the design of the study, data collection, development of the coding frame, analysis and interpretation of the data. GP and GH contributed to the study design, data collection, developing the coding frame, data analysis and data interpretation. SD participated in the development of the coding frame, data analysis and data interpretation. DÓC, GP, BK and SD contributed to drafting the paper. All authors read, revised and approved the final version of the manuscript.

\section{Funding}

The Irish Hospice Foundation and the Health Service Executive, Quality Improvement Division provided funding to assist with the dissemination of this research. However, neither organisation had any influence on or role in the design of the study, collection, analysis, and interpretation of data and or in writing the manuscript.

\section{Availability of data and materials}

The dataset generated and analysed for this study is not publicly available as the conditions of consent from the local ethics review committee of the institutions involved and the formal consent process did not include sharing the dataset.

\section{Ethics approval and consent to participate}

The Mater Misericordiae University Hospital Research Ethics Committee (Reference number: 1/378/1685) and Tallaght University Hospital / St. James's Hospital Joint Research Ethics Committee (REC Reference: 2014-12 Chairman's Action 8) granted full ethical approval for the study. Consent by study participants was obtained. Participants were informed that return of the questionnaire was viewed as consent to participate. Any identifiable data were removed from the dataset during analysis.

\section{Consent for publication}

Not applicable.

\section{Competing interests}

The authors declare that they have no competing interests.

\section{Author details}

1End-of-Life Care, Mater Misericordiae University Hospital, Quality and Patient Safety Directorate, Eccles Street, Dublin 7, Ireland. ${ }^{2}$ Trinity Centre for Practice and Healthcare Innovation, School of Nursing and Midwifery, Trinity College Dublin, Dublin, Ireland. ${ }^{3}$ End-of-Life Care, Hospice Friendly Hospital Programme, 1st Floor CEO Building, St. James's Hospital, James Street, Dublin 8 , Ireland. ${ }^{4}$ Social Work, School of Social Policy, Social Work and Social Justice, University College, Dublin, Ireland. ${ }^{5}$ Palliative Care, School of Nursing \& Midwifery, Trinity College Dublin, Dublin, Ireland.

Received: 6 December 2018 Accepted: 12 September 2019 Published online: 31 October 2019

\section{References}

1. Gomes B, Higgins IJ. Where people die (1974-2010): past trends, future projections and implications for care. Palliat Med. 2008;22(1):33-41 doi: 10. 1177\%2F0269216307084606.

2. Beccaro M, Caraceni A, Costantin M. End-of-life in Italian hospitals: quality of and satisfaction with care from the caregivers'point of view- results from the Italian survey of the dying of Cancer. J Pain Symptom Manag. 2010; 39(6):1003-15B. https://doi.org/10.1016/j.jpainsymman.2009.11.317.

3. Broad JB, Gott M, Kim H, Boyd M, Chen H, Connolly MJ. Where do people die? An international comparison of the percentage of deaths occurring in hospital and residential aged care settings in 45 populations, using published and available statistics. Int J Public Health. 2013;58:257-67. https://doi.org/10.1007/s00038-012-0394-5.

4. Ziwary SR, Samad D, Johnson CD, Edwards RT. Impact of place of residence on place of death. BMC Palliat Care. 2017;16:72. https://doi.org/10.1186/ s12904-017-0261-5.

5. Al-Qurainy A, Collis E, Feuer D. Dying in an acute hospital setting: the challenges and solutions. Int J Clin Pract. 2009;63(3):508-15. https://doi.org/ 10.1111/j.1742-1241.2008.01991.x

6. Irish Hospice Foundation. Enabling More People to Die at Home: Making the Case for Quality Indicators as Drivers for Change on Place of Care and Place of Death in Ireland. Dublin: Irish Hospice Foundation; 2014a. http:// hospicefoundation.ie/wp-content/uploads/2014/12/Enabling-More-Peopleto-Die-at-Home1.pdf

7. Francis R. Report of the mid Staffordshire NHS Foundation trust public inquiry. London: Crown Publications; 2013. www.midstaffspublicinquiry.com/

8. Neuberger J. More care, less pathway: a review of the Liverpool care pathway London: Department of Health; 2013. https://www.gov.uk/ government/uploads/system/uploads/attachment_data/file/212450/ Liverpool_Care_Pathway.pdf

9. Royal College of Physicians. End of life care audit-dying in hospital: National Report for England. London: Royal College of Physicians; 2016. https://www. rcplondon.ac.uk/projects/outputs/end-life-care-audit-dying-hospital-nationalreport-england-2016

10. Parliamentary and Health Service Ombudsman. Dying without dignity: Investigations by the Parliamentary and Health Service Ombudsman into complaints about end of life care. London: Parliamentary and Health Service Ombudsman; 2015. https://www.ombudsman.org.uk/sites/default/files/ Dying_without_dignity.pdf

11. Office of the Ombudsman. A good death: a reflection on ombudsman complaints about end of life care in Irish hospitals. Dublin: Office of the Ombudsman; 2014. https://www.ombudsman.ie/publications/reports/agood-death/A-Good-Death-Report.pdf

12. McKeown K, Haase T, Pratschke J, Twomey S, Donovan H, Engling F. National Audit of end-of-life Care in Hospitals in Ireland, 2008/9. Dying in Hospital in Ireland: an assessment of the quality of Care in the Last Week of life. Dublin: Irish Hospice Foundation; 2010. http://hospicefoundation.ie/wpcontent/uploads/2013/04/FINAL_National_Audit_of_End_of_Life_Care_in_ Hospitals_Report_5.pdf

13. Ó Coimín D, Korn B, Prizeman G, Donnelly S, Hynes G, Curran M, Codd M. Survey of Bereaved Relatives: VOICES MaJam. Dublin: Mater Misericordiae University Hospital and St. James's Hospital; 2017. https://www.lenus.ie/ handle/10147/621493

14. Engelberg RA, Downey L, Wenrich MD, Carline JD, Silvestri GA, Dotolo D, Nielsen EL, Curtis JR. Measuring the quality of end-of-life care. J Pain Symptom Manag. 2010 Jun;39(6):951-71. https://doi.org/10.1016/j. jpainsymman.2009.11.313. 
15. Bussmann S, Muders P, Zahrt-Omar CA, Escobar PL, Claus M, Schildmann J, Weber M. Improving end-of-life Care in Hospitals: a qualitative analysis of bereaved families' experiences and suggestion. Am J Hosp Palliat Care. 2015;32(1):44-51. https://doi.org/10.1177/1049909113512718.

16. Mistry B, Bainbridge D, Bryant D, Toyofuku ST, Seow H. What matters most for end-of-life care? Perspectives from community-based palliative care providers and administrators. BMJ Open. 2015;5(6):e007492. https://doi.org/ 10.1136/bmjopen-2014-007492.

17. Virdun C, Luckett T, Lorenz K, Davidson PM, Phillips J. Dying in the hospital setting: a meta-synthesis identifying the elements of end-of-life care that patients and their families describe as important. Palliat Med. 2017;31(7): 587-601. https://doi.org/10.1177/0269216316673547.

18. Kamal AH, Hanson LC, Casarett DJ, Dy SM, Pantilat SZ, Lupu D, Abernethy AP. The quality imperative for palliative care. J Pain Symptom Manag. 2015; 49(2):243-53. https://doi.org/10.1016/j.jpainsymman.2014.06.008.

19. National Clinical Care Programme for Palliative Care. Glossary of terms: palliative care clinical care Programme. Dublin: Health Service Executive Clinical Strategy and Programmes Division; 2014. https://www.hse.ie/eng/about/who/ cspd/ncps/palliative-care/resources/glossary/palliative-care-glossary.pdf

20. General Medical Council. Treatment and care towards the end of life: good practice in decision making. London: General Medical Council; 2010. https:// www.gmc-uk.org/ethical-guidance/ethical-guidance-for-doctors/treatmentand-care-towards-the-end-of-life

21. National Institute for Clinical Excellence. Care of Dying Adults in the last days of life (NG31). London: National Institute for Clinical Excellence; 2015. https://www.nice.org.uk/guidance/ng31

22. Scottish Government. The strategic framework for action on palliative and end of life care, 2016-2021. The Scottish Government: Edinburgh Scotland; 2015. http://www.gov.scot/Resource/0049/00491388.pdf

23. Australian Institute of Health and Welfare. Australia's Health 2016. End-of-life Care. Australia's health series no. 15. Cat. no. AUS 199. Canberra: AlHW; 2016. https://www.aihw.gov.au/getmedia/68ed1246-886e-43ff-af35-d52db9a96 00c/ah16-6-18-end-of-life-care.pdf.aspx

24. Burge F, Lawson B, Johnston G, Asada Y, Mclntyre PF, Grunfeld E, Flowerdew G. Bereaved family member perceptions of patient-focused family-centred care during the last 30 days of life using a mortality followback survey: does location matter? BMC Palliative Care. 2014;13:25 http:// www.biomedcentral.com/1472-684X/13/25.

25. Seow H, Bainbridge D, Bryant D, Guthrie D, Urowitz S, Zwicker V, Marshall D. The Caregiver Voice Survey: A Pilot Study Surveying Bereaved Caregivers To Measure the Caregiver and Patient Experience at End of Life. J Palliat Med. 2016;19(7). https://doi.org/10.1089/jpm.2015.0366.

26. Koffman J, Morgan M, Edmonds P, Speck P, Higginson IJ. Vulnerability in palliative care research: findings from a qualitative study of black Caribbean and white British patients with advanced cancer. J Med Ethics. 2009;35:4404. https://doi.org/10.1136/jme.2008.027839.

27. Payne S, Field D. Undertaking bereavement research: sensitivities and sensibilities: grief matters. Aust J Grief Bereavement. 2004;17(3):52-6.

28. Stajduhar KI, Funk L, Cohen SR, Williams A, Bidgood D, Allan D, Norgrove L, Heyland D. Bereaved family members' assessments of the quality of end-of-life care: what is important? J Palliat Care. 2011;27(4):261-9 http://soignantfindevie. com/media/4836/Stajduhar-et-al-2011-Bereaved-family-members-assessmentsof-the-quality-of-end-of-life-care-What-is-important.pdf.

29. Calanzani N, Higginson IJ, Koffman J, Gomes B. Factors associated with participation, active refusal and reasons for not taking part in a mortality Followback survey evaluating end-of-life care. PLoS One. 2016;11(1): e0146134. https://doi.org/10.1371/journal.pone.0146134.

30. Office for National Statistics. National Bereavement Survey (VOICES). England: Office for National Statistics; 2016. https://www.ons.gov.uk/ peoplepopulationandcommunity/healthandsocialcare/healthcaresystem/ bulletins/nationalsurveyofbereavedpeoplevoices/england2015

31. Holdsworth LM. Bereaved carers' accounts of the end of life and the role of care providers in a 'good death': A qualitative study. Palliat Med. 2015;29(9): 834-41. https://doi.org/10.1177/0269216315584865.

32. Mayland CR, Mulholland H, Gambles M, Ellershaw J, Stewart K. How well do we currently care for our dying patients in acute hospitals: the views of the bereaved relatives? BMJ Support Palliat Care. 2017;7(3):316-25 www.ncbi. nlm.nih.gov/pubmed/28096171.

33. Gallagher R, Krawczyk M. Family members' perceptions of end-of-life care across diverse locations of care. BMC Palliat Care. 2013;12(1):24. https://doi. org/10.1186/1472-684X-12-25.
34. Tang ST, Corkle R. Use of family proxies in quality of life research for cancer patients at the end of life: a literature review. Cancer Investig. 2002;20(7-8): 1086-104. https://doi.org/10.1081/CNV-120005928.

35. Kross E, Nielsen E, Curtis R, Engelberg R. Survey burden for family members surveyed bout end-of-life care in the intensive care unit. J Pain Symptom Manag. 2012;44(5):671-80. https://doi.org/10.1016/j.jpainsymman.2011.11.008.

36. Germain A, Mayland CR, Jack BA. The potential therapeutic value for bereaved relatives participating in research: An exploratory study. BMJ Support Palliat Care. 2016;14(5):479-87. https://doi.org/10.1017/ S1478951515001194.

37. National Economic and Social Council. Quality and standards in human Services in Ireland: end-of-life Care in Hospitals. Dublin: National Economic and Social Council; 2012. https://www.nesc.ie/ publications/quality-and-standards-in-human-services-in-ireland-end-oflife-care-in-hospitals/

38. Clark D, Graham F. The hospice friendly hospitals Programme in Ireland: a narrative history. Irish Hospice Foundation: Dublin; 2014. http:// hospicefoundation.ie/wp-content/uploads/2014/09/The-Hospice-Friendlyhospitals-programme-in-Ireland-a-narrative-history.pdf

39. Walsh K. The hospice friendly hospitals Programme; overview 2007-2013. The Irish Hospice Foundation; 2014. http://hospicefoundation.ie/wpcontent/uploads/2013/04/The-Hospice-Friendly-Hospitals-Programme.Overview-2007-2013.pdf

40. Irish Hospice Foundation. Quality Standards for End-of-Life Care in Hospitals: Making end-of-life care central to hospital care. Dublin: Irish Hospice Foundation; 2010. http://hospicefoundation.ie/wp-content/uploads/2013/ 04/Quality_Standards_for_End_of_Life_Care_in_Hospitals.pdf

41. Irish Hospice Foundation. Hospice Friendly Hospitals - The case for continued investment. Irish Hospice Foundation; 2014b. http:// hospicefoundation.ie/wp-content/uploads/2013/04/Hospice-FriendlyHospitals.-Advocacy-Paper.-November-2014.pdf

42. Hunt KJ, Addington-Hall J. A toolkit for the design and planning of locallyled VOICES end of life care surveys. Southampton: University of Southampton; 2011. https://www.gov.uk/government/uploads/system/ uploads/attachment_data/file/215505/dh_130569.pdf

43. Hunt KJ, Shlomo N, Richardson A, Addington-Hall JM. VOICES redesign and testing to inform a National end of life care survey. Southampton: University of Southampton; 2011. https://www.gov.uk/government/uploads/system/ uploads/attachment_data/file/215503/dh_128825.pdf

44. McPherson CJ, Addington-Hall JM. Judging the quality of care at the end of life: can proxies provide reliable information? Soc Sci Med. 2003;56(1):95109 https://www.ncbi.nlm.nih.gov/pubmed/12435554.

45. Young AJ, Rogers A, Dent L, Addington Hall JM. Experiences of hospital care reported by bereaved relatives of patients after a stroke: a retrospective survey using the VOICES questionnaire. J Adv Nurs. 2009;65(10):2161-74.

46. Burt J, Shipman C, Richardson A, Ream E, Addington-Hall J. The experiences of older adults in the community dying from cancer and non-cancer causes: a national survey of bereaved relatives. Age Ageing. 2010;39(1):8691. https://doi.org/10.1093/ageing/afp212.

47. O'Sullivan A, Ohlen J, Alvariza A, Hakanson C. Adaptation and validation of the VOICES (SF) questionnaire - for evaluation of end-of-life care in Sweden. Scand J Caring Sci. 2018;32(3):1254-60. https://doi.org/10.1111/scs.12542.

48. Health Service Executive. National Healthcare Charter - You and Your Health Service. Dublin: Health Service Executive; 2012. https://www.hse.ie/eng/ services/yourhealthservice/hcharter/

49. Health Information Quality Authority. National Standards for safer better healthcare. Dublin: Health Information and Quality Authority; 2012. https:// www.hiqa.ie/reports-and-publications/standard/national-standards-saferbetter-healthcare

50. Addington-Hall JM, O'Callaghan AC. A comparison of the quality of care provided to cancer patients in the UK in the last three months of life in inpatient hospices compared with hospitals, from the perspective of bereaved relatives: results from a survey using the VOICES questionnaire. Palliat Med. 2009;23(3):190-7. https://doi.org/10.1177/0269216309102525.

51. Bentley B, O'Connor M. Conducting research interviews with bereaved family Carers: when do we ask? J Palliat Med. 2014;18(3):241-5. https://doi. org/10.1089/jpm.2014.0320.

52. Hunt KJ, Shlomo N, Addington-Hall J. End-of-life care and achieving preferences for place of death in England: results of a population-based survey using the VOICES-SF questionnaire. Palliat Med. 2014;28(5):412-21. https://doi.org/10.1177/0269216313512012. 
53. Sadler E, Hales B, Henry B, Xiong W, Myers J, Wynnychuk L, Taggar R, Heyland D, Fowler R. Factors affecting family satisfaction with inpatient endof-life care. PLoS One. 2014;9(11):e110860. https://doi.org/10.1371/journal. pone.0110860.

54. IBM Corp. IBM SPSS statistics for windows, version 22.0. Armonk: IBM Corp; 2011.

55. NVivo. NVivo Qualitative Data Analysis Software; QSR International Pty Ltd. Version 10; 2012

56. King N. Using templates in the thematic analysis of text. In: Cassell C, Symon G, editors. Essential guide to qualitative methods in organizational research. London: Sage; 2004. p. 256-70.

57. Donnelly S, Prizeman G, Ó Coimín D, Korn B, Hynes G. Voices that Matter: End-of-life Care in Two Acute Hospitals Care Experiences from the Perspective of Bereaved Relatives. BMC Palliative Care. 2018;17:117 https:// bmcpalliatcare.biomedcentral.com/articles/10.1186/s12904-018-0365-6.

58. Robinson J, Gott M, Ingleton C. Patient and family experiences of palliative care in hospital: what do we know? An integrative review. Palliat Med. 2014; 28(1):18-33. https://doi.org/10.1177/0269216313487568.

59. Teno JM, Clarridge BR, Casey V, Welch LC, Wetle T, Shield R, Mor V. Family perspectives on end-of- life care at the last place of care. JAMA. 2004;291(1): 88-93 https://www.ncbi.nlm.nih.gov/pubmed/14709580.

60. Baker R, Wu AW, Teno JM, Kreling B, Damiano AM, Rubin HR, Roach MJ, Wenger NS, Phillips RS, Desbiens NA, Connors AF Jr, Knaus W, Lynn J. Family satisfaction with end-of-life care in seriously ill hospitalized adults. J Am Geriatr Soc. 2000;48(5Suppl):S61-9 https://www.ncbi.nlm.nih.gov/ pubmed/10809458.

61. World Health Organization. Cancer: WHO Definition of Palliative Care. WHO; 2013. http://www.who.int/cancer/palliative/definition/en/

62. Mularski R, Dy S, Shugarman L, Wilkinson A, Lynn J, Shekelle P, Morton S, Sun V, Hughes R, Hilton L, Maglione M, Rhodes S, Rolon C, Lorenz K. A Systematic Review of Measures of End-of-Life Care and Its Outcomes. Health Serv Res. 2007:42(5):1848-70. https://doi.org/10.1111/j.1475-6773.2007.00721.x

63. Seale C, Kelly M. A comparison of hospice and hospital care for the spouses of people who die. Palliat Med. 1997 Mar;11(2):101-6. https://doi.org/10. $1177 / 026921639701100203$.

64. Lynn J, Teno JM, Phillips RS, Wu AW, Desbiens NA, Harrold J, Claessens MT, Wenger N, Kreling B, Connors AF Jr. Perceptions by family members of the dying experience of older and seriously ill patients. SUPPORT investigators. Study to understand prognoses and preferences for outcomes and risks of treatments. Ann Intern Med. 1997;126(2):97-106

65. Royal College of Physicians. National care of the dying audit for hospitals. London: Royal College of Physicians; 2014. https://www.rcplondon.ac.uk/ projects/outputs/national-care-dying-audit-hospitals

66. O'Dowd A. Chronic underfunding in palliative care is key cause of poor care of dying people. BMJ. 2015;351:h4969. https://doi.org/10.1136/bmi.h4969.

67. Brick A, Normand C, O'Hara S, Smith S. Economic Evaluation of Palliative Care in Ireland. Dublin: Trinity College Dublin; 2015. https://www.tcd.ie/ medicine/health_policy_management/assets/pdf/palliative-care-report.pdf

68. Health Service Executive. Palliative Care Services: Three Year Development Framework (2017-2019); 2017. https://www.lenus.ie/handle/10147/622650

69. Healthcare Quality Improvement Partnership. NHS Benchmarking Network, National Audit of Care at the End of Life: First round of audit report England and Wales. 2019.

70. van Riet PJ, Vernooij-Dassen M, Dröes R-M, Radbruch L, Vissers K, Engels Y. Consensus on quality indicators to assess the organisation of palliative cancer and dementia care applicable across national healthcare systems and selected by international experts. BMC Health Serv Res. 2014;14:396. https://doi.org/10.1186/1472-6963-14-396.

71. Dunne K, Sullivan K. Family experiences of palliative care in the acute hospital setting. Int J Palliat Nurs. 2000;6(4):170-8 https://www.ncbi.nlm.nih. gov/pubmed/11143643.

72. Jacobs L, Bonuck K, Burton W, Mulvihill M. Hospital Care at the end of life: an institutional assessment. J Pain Symptom Manag. 2002; 24(3):291-8 http://www.jpsmjournal.com/article/S0885-3924(02)004 94-3/fulltext.

73. Health Services Executive. Palliative Care Needs Assessment Guidance. Dublin: Health Service Executive; 2013. https://www.hse.ie/eng/services/ publications/clinical-strategy-and-programmes/palliative-care-needsassessment-guidance.pdf

74. Steinhauser KE, Christakis NA, Clipp EC, McNeilly M, Grambow S, Parker J, Tulsky JA. Preparing for the end of life: preferences of patients, families, physicians, and other care providers. J Pain Symptom Manag. 2001;22(3): 727-37. https://doi.org/10.1016/S0885-3924(01)00334-7.

75. Hudson P, Remedios C, Zordan R, Thomas K, Clifton D, Crewdson M, Hall C, Trauer T, Bolleter A, Clarke DM, Bauld C. Guidelines for the psychosocial and bereavement support of family caregivers of palliative care patients. Pall Med. 2012;15(6):696-702. https://doi.org/10.1089/jpm. 2011.0466.

76. All Ireland Institute of Hospice and Palliative Care (AllHPC). Let's Talk About: Palliative Care Survey Report. Dublin: AllHPC; 2016. https://www.lenus.ie/ handle/10147/612327? show=full

77. Davison S. End-of-life care preferences and needs: perceptions of patients with chronic kidney disease. Clin J Am Soc Nephrol. 2010;5(2):195-204. https://doi.org/10.2215/CJN.05960809.

78. Maguire P. Barriers to psychological care of the dying. BMJ. 1985;291:1711-3 https://www.ncbi.n/m.nih.gov/pmc/articles/PMC1418798/pdf/bmjcred004780047.pdf.

79. Sinclair S, Bouchal SR, Chochinov HM, Hagen N, McClement S. Spiritual care: how to do it. BMJ Supportive and Palliative Care. 2012;2:319-27. https://doi. org/10.1136/bmjspcare-2011-000191.

80. Department of Health. End of Life Care Strategy: Promoting High Quality Care for All Adults at the End of Life. UK Department of Health: Crown Publications; England. 2008. https://www.gov.uk/government/uploads/ system/uploads/attachment_data/file/136431/End_of_life_strategy.pdf.

81. Ross L, Austin J. Spiritual needs and spiritual support preferences of people with end-stage heart failure and their carers: implications for nurse managers. J Nurs Manag. 2015;23(1):87-95. https://doi.org/10. 1111/jonm.12087.

82. Balboni TA, Vanderwerker LC, Block SD, Paulk ME, Lathan CS, Peteet JR, Prigerson HG. Religiousness and spiritual support among advanced Cancer patients and associations with end-of-life treatment preferences and quality of life. J Clin Oncol. 2007;25(5):555-60. https://doi.org/10. 1200/JCO.2006.07.9046

83. Cockell N, McSherry W. Spiritual care in nursing: an overview of published international research. J Nurs Manag. 2012 Dec;20(8):958-69. https://doi.org/ 10.1111/j.1365-2834.2012.01450.x.

84. McClain CS, Rosenfeld B, Breitbart W. Effect of spiritual well-being on endof-life despair in terminally-ill cancer patients. Lancet. 2003;361(9369):603-7. https://doi.org/10.1016/S0140-6736(03)13310-7.

85. Koenig H, King D, Carson V. Handbook of Religion and health second edition. New York: Oxford University Press; 2012.

86. Koenig H. Religion, Spirituality, and Health: The Research and Clinical Implications. ISRN Psychiatry; 2012; Article ID 278730. https://doi.org/10. 5402/2012/278730.

87. Palliative Care Competence Framework Steering Group. Palliative care competence framework. Dublin: Health Service Executive; 2014. https:// www.hse.ie/eng/services/publications/clinical-strategy-and-programmes/ palliative-care-framework-document.pdf

88. Mills M, Davies HTO, Macrae WA. Care of dying patients in hospital. BMJ. 1994;309(3):583-6 https:/www.ncbi.nlm.nih.gov/pmc/articles/PMC2541438/ pdf/bmj00455-0037.pdf.

89. Leadership Alliance for the Care of Dying People (LACDP). One chance to get it right Improving people's experience of care in the last few days and hours of life. UK: LACDP; 2014. http://wales.pallcare.info/files/One_chance_ to_get_it_right.pdf

90. Handy CM, Sulmasy DP, Merkel CK, Ury WA. The surrogate's experience in authorizing a do not resuscitate order. Palliative Support Care. 2008;6(1):139. https://doi.org/10.1017/S1478951508000035.

91. Vig EK, Starks H, Taylor JS, Hopley EK, Fryer-Edwards K. Surviving surrogate decision-making: what helps and hampers the experience of making medical decisions for others. J Gen Intern Med. 2007;22(9):1274-9. https:// doi.org/10.1007/s11606-007-0252-y.

92. Detering KM, Hancock AD, Reade MC, Silvester W. The impact of advance care planning on end of life care in elderly patients: randomised control trial. BMJ Online. 2010;340:c1345. https://doi.org/10.1136/bmj.c1345.

93. Norris K, Merriman MP, Curtis JR, Asp C, Tuhoslke L, Byock IR. Next of kin perspectives on the experience of end-of-life care in a community setting. Palliat Med. 2007;10(5):1101-15. https://doi.org/10.1089/jpm.2006.2546.

94. Loke A, Li Q, Man L. Preparing Family Members for the Death of Their Loved One With Cancer: A Review of Literature and Direction for Future Research. J Hospice Palliat Nurs. 2013;15(2):E1-E11. https://doi.org/10.1097/ NJH.0b013e3182860650. 
95. Hebert RS, Prigerson HG, Schulz R, Arnold RM. Preparing Caregivers for the Death of a Loved One: A Theoretical Framework and Suggestions for Future Research. J Palliat Med. 2006;9(5):1164-71. https://doi.org/10.1089/jpm.2006.9.1164.

96. Gott M, Ingleton C, Bennett Ml, Gardiner C. Transitions to palliative care in acute hospitals in England: qualitative study. BMJ Support Palliat Care. 2011; 1:42-8. https://doi.org/10.1136/bmj.d1773.

97. Nehls W, Gabrijel S, Bauer TT. Ärzte lernen schweigen Kommunikationstraining in der Lungenklinik Heckeshorn. Zeitschrift fuer Palliativemedizin. 2012;13(5). https://doi.org/10.1055/s-0032-1322924.

98. McKeown K, Haase T, Pratschke J, Twomey S, Donovan H, Engling F. Determinants of care outcomes for patients who die in hospitals in Ireland: a retrospective study. BMC Palliative Care. 2015;14:11. https://doi.org/10. 1186/s12904-015-0014-2.

99. Brereton L, Gardiner C, Gott M, Barnes S, Carrol C. The hospital environment for end of life care of older adults and their families: an integrative review. J Adv Nurs. 2011;68(5):981-93. https://doi.org/10.1111/j.1365-2648.2011.05900.x.

100. Heyland D, Groll D, Rocker G, Dodek P, Gafni A, Tranmer J, Pichora D, Lazar N, Kutsogiannis J, Shortt S, Lam M. Canadian Researchers at the End of Life Network (CARENET). End-of-life care in acute care hospitals in Canada: A quality finish? J Palliat Care. 2005;21(3):142-50 https://www.ncbi.nlm.nih. gov/pubmed/16334968.

101. Ulrich R. The Economic case for renewing Ireland's healthcare infrastructure. Dublin: Irish Hospice Foundation; 2008. https://hospicefoundation.ie/ publications/hfh/

102. Tribal Consulting/Hospice Friendly Hospitals Programme. Design \& Dignity Baseline Review. Dublin: Irish Hospice Foundation; 2007. http:// hospicefoundation.ie/wp-content/uploads/2013/04/Design-and-DignityBaseline-Review-Nov-071.pdf

103. McLoughlin K. Hearing the voice of bereaved relatives. Dublin: Irish Hospice Foundation; 2015. http://hospicefoundation.ie/wp-content/uploads/2013/ 04/Hearing-the-Voice-of-Bereaved-Relatives-March-2015.pdf

104. Casey D, Murphy K, Leime AN, Larkin P, Payne S, Froggatt KA, O'Shea E. Dying well: factors that influence the provision of good end-of-life care for older people in acute and long-stay care settings in Ireland. J Clin Nurs. 2011;20:1824-33 https://onlinelibrary.wiley.com/doi/full/10.1111/j.1365-2 702.2010.03628.x.

105. Formiga F, Olmedo C, Lopez-Soto A, Navarro M, Culla A, Pujol R. Dying in hospital of terminal heart failure or severe dementia: the circumstances associated with death and the opinions of caregivers. Palliat Med. 2007; 21(1):35-40 https://www.ncbi.nlm.nih.gov/pubmed/17169958.

106. Clark K, Willis A, Byfieldt N. An observational study to explore the feasibility of assessing bereaved Relatives' experiences before and after a quality improvement project to improve Care of Dying Medical Inpatients. Am J Hosp Palliat Care. 2017;34(3):263-8. https://doi.org/10.1177/ 1049909115625280.

107. Parker S. Design and dignity: how Irish hospitals are transforming spaces for patients and families at the end of life. Dublin: Irish Hospice Foundation; 2017. http://hospicefoundation.ie/wp-content/uploads/2014/12/Design-andDignity-Case-Study-by-Atlantic-Philantropies-May-2017.pdf

108. Clark D, Armstrong M, Allan A, Graham F, Carnon A, Isles C. Imminence of death among hospital inpatients: prevalent cohort study. Palliat Med. 2014; 28(6):474-9. https://doi.org/10.1177/0269216314526443.

109. Irish Hospice Foundation. Design \& Dignity Style Book: Transforming End-ofLife Care in Hospitals One Room at a Time. Dublin: Irish Hospice Foundation; 2014c. http://hospicefoundation.ie/wp-content/uploads/2 014/12/Design-Dignity-Style-Book-July-2014.pdf

110. Programme HFH. Design and dignity guidelines for physical environments of hospitals supporting end-of-life care. Dublin: Irish Hospice Foundation; 2008. http://hospicefoundation.ie/wp-content/uploads/2013/04/Design-andDignity-Guidelines-for-Physical-Environments-of-Hospitals-Supporting-EndofLife-Care-HfH-2008.pdf

111. Waller S, Dewar S, Masterson A, Finn H. Improving environments for Care at end of life. Lessons from eight UK pilot sites. London: King's Fund; 2008. https://www.kingsfund.org.uk/sites/files/kf/improving-environments-care-atend-of-life-eight-uk-pilot-sites-waller-dewar-masterson-finn-april-2008.pdf

112. Kusano AS, Kenworthy-Heinige T, Thomas CR. Survey of bereavement practices of cancer care and palliative care physicians in the Pacific Northwest United States. J Oncol Pract. 2012;8(5):275-81. https://doi.org/10. 1200/JOP.2011.000512.

113. Granot T, Gordon N, Perry S, Rizel S, Stemmer SM. Factors affecting communication patterns between oncology staff and family members of deceased patients: a cross-sectional study. PLoS One. 2016;11(9):e0162813. https://doi.org/10.1371/journal.pone.0162813.

114. Small N, Barns S, Gott M, Payne S, Parker C, Seamark D, Gariballa S. Dying, death and bereavement: a qualitative study of the views of carers of people with heart failure in the UK. BMC Palliat Care. 2009;8:6. https://doi.org/10.1186/1472-684X-8-6.

115. Aoun SM, Rumbold B, Howting D, Bolleter A, Breen $\sqcup$. Bereavement support for family caregivers: The gap between guidelines and practice in palliative care. PLoS ONE. 2017; 12(10). doi: https://doi.org/10.1371/journal.pone.0184750.

116. Harrop E, Morgan F, Byrne A, Nelson AM. "It still haunts me whether we did the right thing": a qualitative analysis of free text survey data on the bereavement experiences and support needs of family caregivers. BMC Palliat Care. 2016;15:92. https://doi.org/10.1186/s12904-016-0165-9.

117. Tolle SW, Bascom PB, Hickam DH, Benson JA Jr. Communication between physicians and surviving spouses following patient deaths. J Gen Intern Med. 1986;1:309. https://doi.org/10.1007/BF02596210.

118. Walsh T, Foreman M, Curry P, O'Driscoll S, McCormack M. Bereavement support in an acute hospital: an Irish model. Death Stud. 2008;32(8):768-86. https://doi.org/10.1080/07481180802289788.

119. Kentish-Barnes N, Chevret S, Azoulay E. Impact of the condolence letter on the experience of bereaved families after a death in intensive care: study protocol for a randomized control trial. Trials. 2016;17(1):102. https://doi.org/ 10.1186/s13063-016-1212-9.

120. Rawlings D, Glynn T. The development of a palliative care-led memorial service in an acute hospital setting. Int J Palliat Nurs. 2002;8(1):40-7. https:// doi.org/10.12968/ijpn.2002.8.1.10236.

121. Higginson I, Priest P, McCarthy M. Are bereaved family members a valid proxy for a patient's assessment of dying? Soc Sci Med. 1994;38(4):553-7.

122. Hinton J. How reliable are relatives' retrospective reports of terminal illness? Patients' and relatives' accounts compared. Soc Sci Med. 1996;43:1229-36.

123. Fakhoury W, McCarthy M, Addington-Hall J. Determinants of informal caregivers' satisfaction with services for dying cancer patients. Soc Sci Med. 1996;42:721-31.

124. Rogers A, Karlson S, Addington-Hall J. 'All the services were excellent. It is when the human element comes in that things go wrong': dissatisfaction with hospital care in the last year of life. J Adv Nurs. 2000;31(4):768-74.S.

125. Sneeuw KCA, Aaronson NK, Sprangers MAG, Detmar SB, Wever LDV, Schornagel $\mathrm{JH}$. Evaluating the quality of life of cancer patients: assessments by patients, significant others, physicians and nurses. Br J Cancer. 1999;81(1):87-94.

126. Addington-Hall J, McPherson C. After-death interviews with surrogates/bereaved family members: some issues of validity. J Pain Symptom Manag. 2001;22(3):784-90.

127. Health Services Executive. When someone you care about is dying in hospital What to expect. Health Service Executive and Hospice Friendly Hospitals Programme; 2018. https:/www.healthpromotion.ie/hp-files/docs/HPM01187.pdf

\section{Publisher's Note}

Springer Nature remains neutral with regard to jurisdictional claims in published maps and institutional affiliations.

Ready to submit your research? Choose BMC and benefit from:

- fast, convenient online submission

- thorough peer review by experienced researchers in your field

- rapid publication on acceptance

- support for research data, including large and complex data types

- gold Open Access which fosters wider collaboration and increased citations

- maximum visibility for your research: over $100 \mathrm{M}$ website views per year

At $\mathrm{BMC}$, research is always in progress.

Learn more biomedcentral.com/submissions 